\title{
National Evidence on the Use of Shared Decision Making in Prostate-Specific Antigen Screening
}

\author{
Paul K. J. Han, MD, MA, MPH \\ Sarab Kobrin, $\mathrm{PbD}^{2}$ \\ Nancy Breen, $\mathrm{PbD}^{3}$ \\ Djenaba A. Joseph, MD, MPH \\ Jun Li, MD, PbD \\ Dominick L. Frosch, PbD $D^{5,6}$ \\ Carrie N. Klabunde, $P b D^{3}$
}

'Maine Medical Center Research Institute, Portland, ME; Tufts University School of Medicine, Boston, Massachusetts

${ }^{2}$ Behavioral Research Program, Division of Cancer Control and Population Sciences, National Cancer Institute, Rockville, Maryland

${ }^{3}$ Applied Research Program, Division of Cancer Control and Population Sciences, National Cancer Institute, Rockville, Maryland

${ }^{4}$ Centers for Disease Control and Prevention, Atlanta, Georgia

${ }^{5}$ Palo Alto Medical Foundation Research Institute, Palo Alto, California

${ }^{6}$ Department of Medicine, University of California, Los Angeles, California

Conflicts of interest: authors report none.

\section{CORRESPONDING AUTHOR}

Paul K. J. Han, MD, MA, MPH

Center for Outcomes Research and

Evaluation

Maine Medical Center

509 Forest Ave

Portland, ME 04101

hanp@mmc.org

\begin{abstract}
PURPOSE Recent clinical practice guidelines on prostate cancer screening using the prostate-specific antigen (PSA) test (PSA screening) have recommended that clinicians practice shared decision making-a process involving clinician-patient discussion of the pros, cons, and uncertainties of screening. We undertook a study to determine the prevalence of shared decision making in both PSA screening and nonscreening, as well as patient characteristics associated with shared decision making.
\end{abstract}

METHODS A nationally representative sample of 3,427 men aged 50 to 74 years participating in the 2010 National Health Interview Survey responded to questions on the extent of shared decision making (past physician-patient discussion of advantages, disadvantages, and scientific uncertainty associated with PSA screening), PSA screening intensity (tests in past 5 years), and sociodemographic and health-related characteristics.

RESULTS Nearly two-thirds (64.3\%) of men reported no past physician-patient discussion of advantages, disadvantages, or scientific uncertainty (no shared decision making); $27.8 \%$ reported discussion of 1 to 2 elements only (partial shared decision making); $8.0 \%$ reported discussion of all 3 elements (full shared decision making). Nearly one-half (44.2\%) reported no PSA screening, $27.8 \%$ reported low-intensity (less-than-annual) screening, and $25.1 \%$ reported high-intensity (nearly annual) screening. Absence of shared decision making was more prevalent in men who were not screened; $88 \%(95 \% \mathrm{Cl}, 86.2 \%-90.1 \%)$ of nonscreened men reported no shared decision making compared with 39\% (95\% Cl, 35.0\%43.3\%) of men undergoing high-intensity screening. Extent of shared decision making was associated with black race, Hispanic ethnicity, higher education, health insurance, and physician recommendation. Screening intensity was associated with older age, higher education, usual source of medical care, and physician recommendation, as well as with partial vs no or full shared decision making.

CONCLUSIONS Most US men report little shared decision making in PSA screening, and the lack of shared decision making is more prevalent in nonscreened than in screened men. Screening intensity is greatest with partial shared decision making, and different elements of shared decision making are associated with distinct patient characteristics. Shared decision making needs to be improved in decisions for and against PSA screening.

Ann Fam Med 2013;306-314. doi:10.1370/afm.1539.

\section{INTRODUCTION}

$\mathrm{S}$ creening for prostate cancer using the prostate-specific antigen test (PSA screening) is a common practice in the United States. Each year approximately $40 \%$ to $50 \%$ of men aged 50 years and older undergo PSA screening, ${ }_{1}^{1}$ often without their knowledge. ${ }^{2-6}$ The test has become so routine that in one highly publicized case a physician was sued for malpractice for not ordering it. ${ }^{7}$ Yet PSA screening remains controversial. ${ }^{8,9}$ 
The PSA test has limited accuracy, and evidence for its effectiveness in reducing mortality is conflicting. ${ }^{10}$ Prostate cancer has a heterogeneous natural history; although fatal in some men, it is indolent in most, and outcomes for individuals are difficult to predict. PSA screening can thus lead to overdiagnosis and unnecessary diagnostic evaluation and treatment. For these reasons, professional organizations, including the US Preventive Services Task Force (USPSTF), American Cancer Society (ACS), and American Urologic Association (AUA), have issued clinical practice guidelines recommending that clinicians inform patients about the pros, cons, and uncertainties of PSA screening, and that screening decisions be based on patient preferences. ${ }^{11-13}$ These elements are essential for informed decision making $^{14,15}$ and for shared decision making. ${ }^{14-16}$

PSA screening decisions in the United States, however, fall short of these ideals. National surveys have shown that many men who undergo PSA screening are poorly informed, and screening decisions are typically made by clinicians alone. ${ }^{17-21}$ PSA screening in the absence of shared decision making exposes men to its potential harms without their knowledge and has been a dominant focus of policy debates. 4,17,19,22 The USPSTF's revised guidelines address this problem by not only discouraging routine screening, but recommending that physicians "should not offer or order PSA screening unless they are prepared to engage in shared decision making." $10,22,23$

A problem that has attracted less attention is nonscreening, or test nonuptake, ${ }^{24}$ in the absence of shared decision making. This problem is equally important if one believes that existing evidence remains insufficient to recommend for or against screening, as critics of the revised USPSTF guidelines have argued ${ }_{1}^{25-27}$ yet empirical data on its extent are lacking. National surveys have measured shared decision making in PSA screening rather than nonscreening-focusing on men who have undergone screening ${ }^{18}$ or considered it during some recent time interval. ${ }^{19}$ They have also used either brief measures of shared decision making ${ }^{18,19}$ or smaller, nonrepresentative sample populations. ${ }^{28}$ We thus have an incomplete understanding of the extent of shared decision making in PSA screening and the implications of alternative policy approaches to this problem.

The objective of the current study was to provide population-level evidence on the prevalence of shared decision making in both PSA screening and nonscreening. Using a large nationally representative health survey of the US public, we ascertained the extent of physicianpatient discussions of the advantages, disadvantages, and uncertainties associated with PSA screening among screened and unscreened men aged 50 to 74 years. We then conducted analyses to (1) estimate the US popula- tion prevalence of both PSA screening and nonscreening in both the presence and absence of shared decision making ( (2) examine the association between critical elements of shared decision making and PSA screening uptake and intensity of use ${ }_{i}$ and (3) identify patient characteristics associated with shared decision making.

\section{METHODS}

\section{Data Source and Study Population}

We used data from the 2010 National Health Interview Survey (NHIS), an annual survey of the public conducted by the National Center for Health Statistics, and a principal source of health information on the US civilian, noninstitutionalized population. ${ }^{29}$ The NHIS collects information on sociodemographic characteristics, health status, and health care utilization, and in 2010 the NHIS included a Cancer Control Supplement, developed and cosponsored by the National Cancer Institute and the Centers for Disease Control and Prevention. The NHIS obtains a nationally representative sample of US adults using complex random, stratified, clustered, multistage sampling with oversampling of African-American and Hispanic households. In-person interviews are conducted by US Census Bureau interviewers. Methodological details are at http://www.cdc.gov/nchs/nhis.htm.

Male respondents were asked whether they ever had a PSA test; those responding yes were asked the date and main reason for their most recent test: (1) part of a routine physical examination/screening test, (2) because of a specific problem, and (3) other. Our analysis included men who reported either testing for routine screening or no past testing. We included men aged 50 to 74 years to reflect the most conservative screening age recommendations of the clinical practice guidelines at the time. ${ }^{11,12}$ We excluded men who reported testing for a specific problem, a personal history of prostate cancer, or more than 5 PSA tests in the past 5 years, given that high-frequency testing is almost always undertaken for diagnostic rather than screening purposes.

\section{Conceptual Definitions and Measures of Shared Decision Making}

Definitions of shared decision making vary in conceptual breadth and number of essential elements. ${ }^{30-33} \mathrm{We}$ defined shared decision making in accordance with ACS, AUA, and USPSTF guidelines for PSA screening that existed during the 2010 NHIS; all recommended that patients be provided with key information about the advantages, disadvantages, and uncertainties of PSA screening, and that patients' preferences be considered. ${ }^{12,13,16}$ These essential elements of informed decision making ${ }^{31,32}$ constitute shared decision making when 
facilitated by health care clinicians. ${ }^{14-16}$ All 3 guidelines in 2010 recommended shared decision making, assigning responsibility to "health care providers,"16 "clinicians," ${ }^{\prime \prime 3}$ or "physicians" ${ }^{\prime \prime 2}$ to inform and involve patients in screening decisions. Correspondingly, we focused on shared decision making and the extent to which physicians provided key information to patients.

Physician discussion of advantages and disadvantages were measured using 2 items: (1) "Did a doctor ever talk with you about the advantages of the PSA test?" and (2) "Did a doctor ever talk with you about the disadvantages of the PSA test?" Physician discussion of uncertainty was measured by a single item: "Did a doctor ever tell you that some experts disagree about whether men should have PSA tests?" Scientific uncertainty is not the only uncertainty pertaining to medical interventions, ${ }^{34}$ and expert disagreement is not the only manifestation of scientific uncertainty. Scientific uncertainty, however, is central to the controversy surrounding PSA screening, $12,13,16,20,23,25,35$ and expert disagreement is a final manifestation of this uncertainty. Questions used yes or no response categories and were asked of all respondents including nonscreened men (for screened men, questions were preceded by the phrase, "Before you had the PSA test..."). All questions underwent 2 rounds of cognitive testing and modification by expert staff. We used responses to the advantages, disadvantages, and uncertainty items to create a composite variable, extent of shared decision making, with 5 categories ranging from no elements to all elements, reflecting the discrete information elements discussed by physicians.

\section{Sociodemographic and Health-Related Variables}

The analysis included sociodemographic and healthrelated factors examined in previous studies ${ }^{18,19,36-41}$ : health insurance, presence of usual source of medical care, family history of prostate cancer, self-reported health status, number of chronic diseases. Physician recommendation for PSA screening was measured by the question, "Has a doctor ever recommended that you have a PSA test?"

\section{PSA Screening Intensity}

To assess PSA screening intensity, we created a 3-level variable from an item asking men whether they ever had a PSA test; those who answered no constituted the lowest intensity category (none). Remaining men were stratified into low- and high-intensity categories based on the total self-reported number of PSA tests in the past 5 years: men reporting 1 to 3 tests were categorized as low intensity (less than annual), men reporting 4 to 5 tests were categorized as high intensity (approximately annual). This approach underestimates high-intensity screening in younger men who may not have undergone 4 to 5 tests even if screened annually. Additional analysis including men aged 40 to 49 years, however, resulted in no significant differences in the proportions of men in the 3 intensity categories.

\section{Data Analysis}

We calculated descriptive statistics of the study population's characteristics, prevalence of shared decision making, and PSA screening intensity. We fit separate multivariable polytomous and binary logistic regression models, adjusting for all sociodemographic and healthrelated characteristics, for the following dependent variables: (1) PSA screening intensity, (2) discussion of advantages and disadvantages, and (3) discussion of uncertainty. For the first model, we included extent of shared decision making as an independent variable. For the second and third models, examining predictors of shared decision making, discussion of uncertainty, and discussion of advantages and disadvantages, respectively, were included as independent variables to examine associations of different shared decision-making elements with one another. We used the Wald $\chi^{2}$ test to assess statistical significance, using a stringent cutoff $(P<.01)$ to minimize type I error from our large sample size. We used SUDAAN 9.0.1 (RTI International) to adjust for the survey's complex sampling design, using weights provided with the NHIS data file to account for selection probability and nonresponse and to provide estimates representative of the US population.

\section{RESULTS}

For the 2010 NHIS, interviews were conducted with 27,157 adults (response rate $60.8 \%$ ). Of 4,217 men aged 50 to 74 years, 3,427 met eligibility criteria and were included in the study population (Figure 1).
Figure 1. Study population of men aged 50-74 years, National Health Interview Survey, 2010.

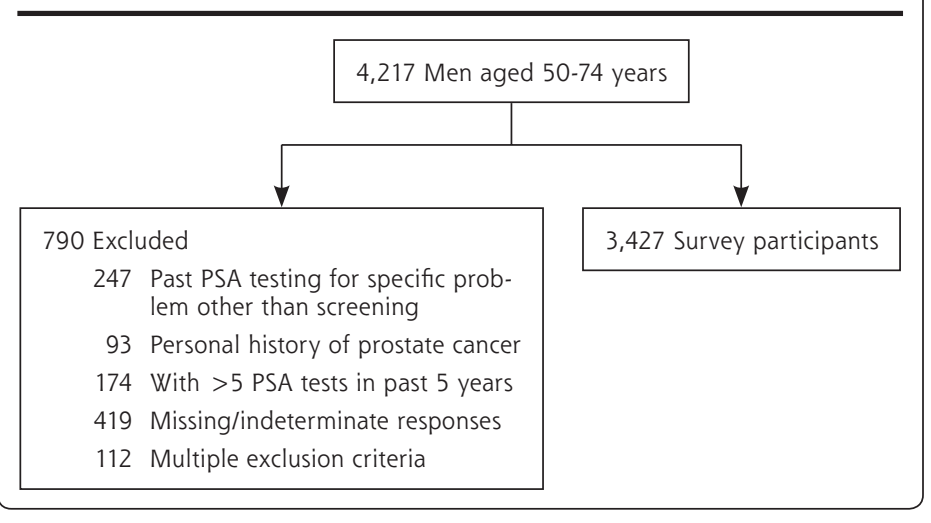


Study population characteristics are shown in Table 1. Approximately $55.8 \%$ of men reported ever having a PSA test, and $65.5 \%$ of them had testing within the past year. Physician recommendation for PSA screening was reported by $52.5 \%$. No past screening was reported by $44.2 \%$, low-intensity screening by $27.8 \%$, high-intensity screening by $25.1 \%$.

Table 2 shows the independent and joint distribution of shared decision-making elements. No physicianpatient discussion of either advantages or disadvantages was reported by $65.1 \%$ of men, whereas discussion of advantages only was reported by $16.9 \%$, disadvantages only by $0.9 \%$, advantages and disadvantages by $17.0 \%$, and uncertainty by $12.1 \%$. Only $8.0 \%$ reported discussion of all 3 elements (full shared decision making). Partial shared decision making ( 1 to 2 discussion elements) was reported by $27.8 \%$, ranging from $2.5 \%$ for disadvantages only to $14.6 \%$ for advantages only.

Table 3 shows the factors associated with PSA screening intensity in adjusted analyses (unadjusted analyses are in Supplemental Table 1, available at

http://annfammed.org/content/11/4/306/suppl/

An DC1). Increasing age, higher education, usual source of medical care, and physician recommendation were associated with higher intensity screening. Partial shared decision making ( 1 to 2 discussion ele-

\begin{tabular}{|c|c|}
\hline Element, No. Responding & Percent $^{a}$ \\
\hline \multicolumn{2}{|l|}{ Discussion of advantages/disadvantages, $\mathrm{n}=3,344$} \\
\hline None & 65.1 \\
\hline Advantages only & 16.9 \\
\hline Disadvantages only & 0.9 \\
\hline Both & 17.0 \\
\hline \multicolumn{2}{|l|}{ Discussion of uncertainty, $n=3,344$} \\
\hline Yes & 12.1 \\
\hline No & 87.9 \\
\hline \multicolumn{2}{|l|}{ Extent of shared decision making, ${ }^{b} \mathrm{n}=3,304$} \\
\hline No elements & 64.3 \\
\hline $\begin{array}{l}\text { Partial, disadvantages only, disadvantages and } \\
\text { uncertainty, or uncertainty only }\end{array}$ & 2.5 \\
\hline Partial, advantages only & 14.6 \\
\hline $\begin{array}{l}\text { Partial, advantages and disadvantages or advan- } \\
\text { tages and uncertainty }\end{array}$ & 10.7 \\
\hline All elements & 8.0 \\
\hline \multicolumn{2}{|l|}{ PSA = prostate-specific antigen.} \\
\hline \multicolumn{2}{|c|}{$\begin{array}{l}\text { Note: Respondents were men aged } 40-75 \text { years with no prior PSA testing or who } \\
\text { had PSA testing as part of routine examination }(N=3,427) \text {; not all categories } \\
\text { sum to } 3,427 \text { because of missing data. }\end{array}$} \\
\hline \multicolumn{2}{|c|}{$\begin{array}{l}\text { a Percentages weighted to the US civilian noninstitutionalized population. } \\
\text { b Physician discussion of the following elements: advantages, disadvantages, } \\
\text { and uncertainty. }\end{array}$} \\
\hline
\end{tabular}

Table 1. Characteristics of Study Population $(\mathrm{N}=3,427), 2010$ National Health Interview Survey

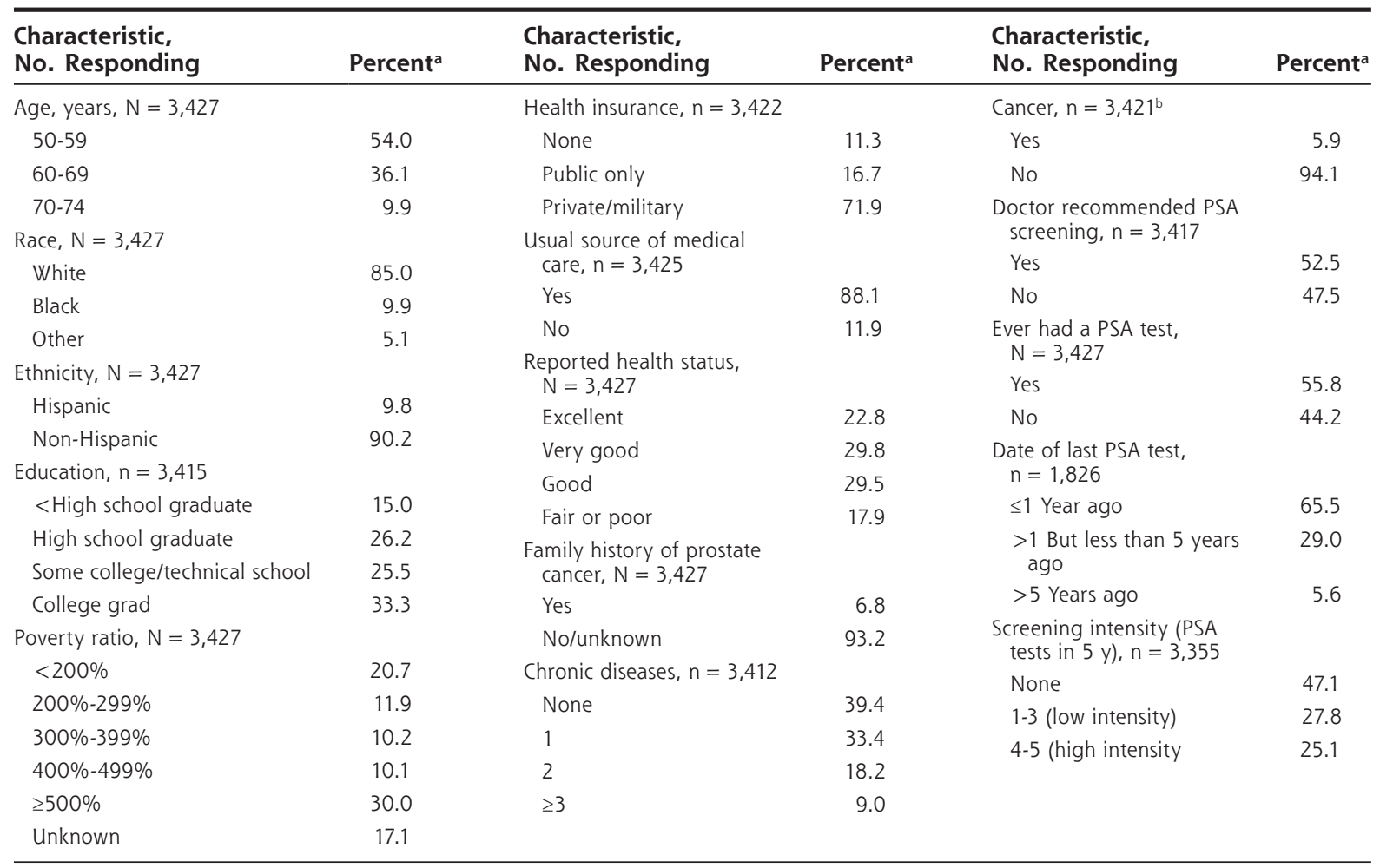

PSA $=$ prostate-specific antigen

Note: Respondents were men aged 40 to 75 years with no prior PSA testing or who had PSA testing as part of routine examination; not all categories sum to 3,427 because of missing data. 
ments) was associated with higher intensity screening (compared with no shared decision making), but full shared decision making (all 3 discussion elements) was not. Figure 2 displays these data in terms of unadjusted column percentages, showing the extent of shared decision making in the nonscreening, low-intensity, and high-intensity screening groups. Of nonscreened men, $88 \%$ (95\% CI, 86.2\%-90.1\%) reported no shared decision-making elements and 3\% (95\% CI, 2.0\%-4.2\%) reported all 3; corresponding proportions for men undergoing high-intensity screening were 39\% (95\% CI, 35.0\%-43.3\%) and 13\% (95\% CI, 9.9\%-15.6\%).

With respect to predictors of shared decision making, 4 factors were positively associated with physicianpatient discussions of advantages and disadvantages (Table 4): black race, Hispanic ethnicity, physician recommendation, and discussion of uncertainty. Two factors-higher education, discussion of advantages and disadvantages — were positively associated with discussion of uncertainty, whereas no or only public health insurance was negatively associated.

\section{DISCUSSION}

The current study adds to mounting evidence that shared decision making is an uncommon occurrence in PSA screening. ${ }^{18,19,21,41}$ Most PSA screening occurs with incomplete or no physician-patient discussion of its associated advantages, disadvantages, and uncertainty. These elements of shared decision making occur at different rates and are associated with different factors, suggesting variation in specific shared decision-making practices for individual patients. The communication of scientific uncertainty is especially infrequent and represents an important target for future shared decision making efforts.

The most significant study finding was that the absence of shared decision making applies not only to PSA screening but also to nonscreening. Because it included-for the first time in a national survey-both screened and nonscreened men, our study was able to show that the relative population prevalence of physician-uninformed nonscreening (screening nonuptake ${ }^{24}$ in the absence of shared decision making) exceeds that of physician-uninformed screening (both low- and high-intensity combined)_corresponding to annual US population-weighted totals of $12,141,033$ vs $6,393,735$ men, respectively. This difference may be partly inflated by screening received unknowingly by some men, ${ }^{2-6}$ but its sheer magnitude is difficult to attribute to underreported testing alone.

These findings provide empirical justification for a broader focus in the current policy debate about PSA screening. Much of this debate has focused on PSA screening in the absence of shared decision making and its potential harm of undesired, unnecessary treatment of screening-detected cancer. Our study, however, suggests that the more prevalent problem is nonscreening in 


\section{Figure 2. Extent of shared decision making by intensity level of PSA screening, 2010 National Health Interview Survey}

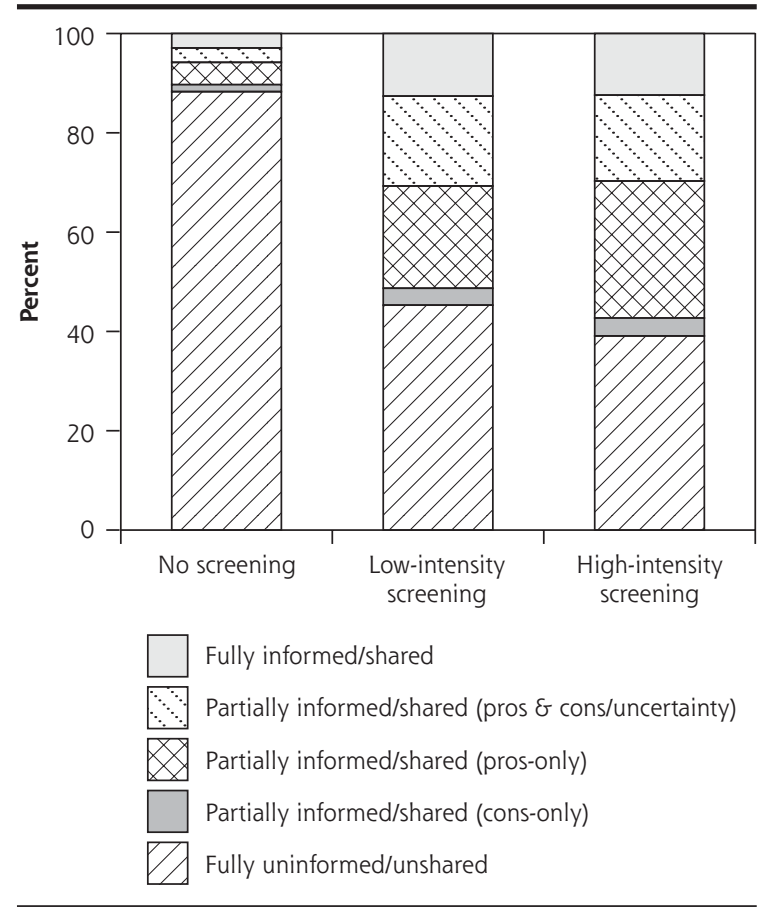

PSA = prostate-specific antigen.

Notes: Extent of shared decision making (unadjusted percentages) according to the physician's discussion of the following elements: advantages, disadvantages, and uncertainty. Fully informed is discussion of all elements. Partially informed/ shared (pros + cons/uncertainty) is discussion of advantages and disadvantages or advantages and uncertainty. Partially informed/shared (pros-only) is discussion of advantages only. Partially informed/shared (cons-only) is discussion of disadvantages only, disadvantages and uncertainty, or uncertainty only. Fully uninformed/unshared is no discussion of decision-making elements. PSA screening intensity levels are as follows: no screening = no past history; lowintensity $=1-3$ tests in past 5 years; high-intensity $=4-5$ tests in past 5 years.

the absence of shared decision making - the harm of which is the failure to allow individuals to decide for themselves if screening is beneficial. The importance of this problem is disputable, as shown by ongoing debate over the revised USPSTF guidelines. ${ }^{249,20,26}$ Physicians have no ethical obligation to discuss or offer nonbeneficial interventions. If, however, the benefits of PSA screening remain disputable based on available evidence-as guidelines in 2010 affirmed and many experts continue to believe ${ }^{25,27}$ — then nonscreening in the absence of shared decision making is problematic.

Our study also provides new evidence of the potential effects of shared decision making on screening. PSA screening is common and associated with several factors, including physician recommendation, older age, higher education, and having a usual source of medical care. These findings reinforce concerns that PSA screening is often undertaken in men less likely to benefit from it and driven in part by access to health care. $^{18,19}$ We showed that screening intensity is associated with shared decision making; it is greater with partial than with full or absent shared decision making (Table 3). This finding is partly consistent with past evidence. Clinical trials have shown that decision support reduces uptake of PSA screening, ${ }^{42-45}$ consistent with our finding that men who reported being fully informed about advantages, disadvantages, and uncertainty had a lower likelihood of undergoing highintensity screening. The association between greater screening and discussion of advantages only was also observed in the national DECISIONS survey. ${ }^{19}$ This association was nonsignificant-likely reflecting power limitations that were due to the DECISIONS study's smaller sample size $(\mathrm{N}=375)$ _but has face validity, suggesting a biasing effect of physician-patient discussions limited to screening advantages.

More difficult to explain is our finding of higher screening intensity even in partial shared decisionmaking discussions limited to screening disadvantages (Table 3). One explanation is that PSA screening discussions are influenced by factors other than their content-eg, the timing or manner in which these discussions are conducted. For example, physicians may communicate screening disadvantages in a manner that downplays their importance. The very discussion of screening by a physician may also convey a promise of benefit, ie, an implicit recommendation for screening. ${ }^{46-51}$ Alternatively, patients may demand PSA screening or have positive preconceptions that may make them disregard information about its disadvantages or resist physicians' attempts to discourage screening. Other unmeasured patient factors, eg, physician-patient racial and sex concordance, may also influence screening discussions. ${ }^{52,53}$ More research is needed to test these and other explanations and to determine how the process of communication about PSA screening, as well as its content, influences decision making. In any case, our findings suggest that this communication process could be improved.

Our study has several limitations. Its reliance on self-report and focus on the occurrence of screening discussions anytime in the past, rather than within a recent time frame, introduces measurement error from recall problems. Our approach, however, has the advantage of maximizing sensitivity for detecting shared decision making that may have occurred in the more distant past and led to subsequent screening refusal, as well as for detecting the absence of shared decision making in nonscreened men. Another limitation is our operationalization of shared decision making in terms of only 3 necessary-but not sufficient-content elements of physician-patient discussions. We did not measure such process elements as 
elicitation of patient preferences. ${ }^{30-32}$ More stringent criteria requiring the joint presence of all these elements would have produced even lower estimates of the prevalence of shared decision making. Further research is needed to develop feasible measures of shared decision making for population surveillance.

Other limitations of our study include its crosssectional design, inability to rule out PSA testing conducted for diagnostic purposes, and use of patient self-report to ascertain both shared decision making and PSA screening. Patient perceptions of care may diverge from actual care; nevertheless, patient perceptions are important outcomes that reflect health care quality and predict behavior. ${ }^{54}$ Yet self-reported screening can be inaccurate ${ }^{55}$ and biased toward underascertainment ${ }^{2-6}$; our exclusion of men reporting more than 5 tests in 5 years may have exacerbated this bias. More research using direct ascertainment of actual screening is needed.

Finally, we did not measure men's knowledge about PSA screening or assess whether informed decision making occurred independently of physicians and clinical encounters. This research gap is critical, because numerous barriers make shared decision making about PSA screening challenging to achieve. Barriers include the large number of screening-eligible men, the indisputably limited clinical time available for patient counseling, and the multiplicity and complex-

Table 4. Factors Associated with Physician-Patient Discussion of Advantages and Disadvantages of PSA Screening and Uncertainty About PSA Screening, 2010 National Health Interview Survey

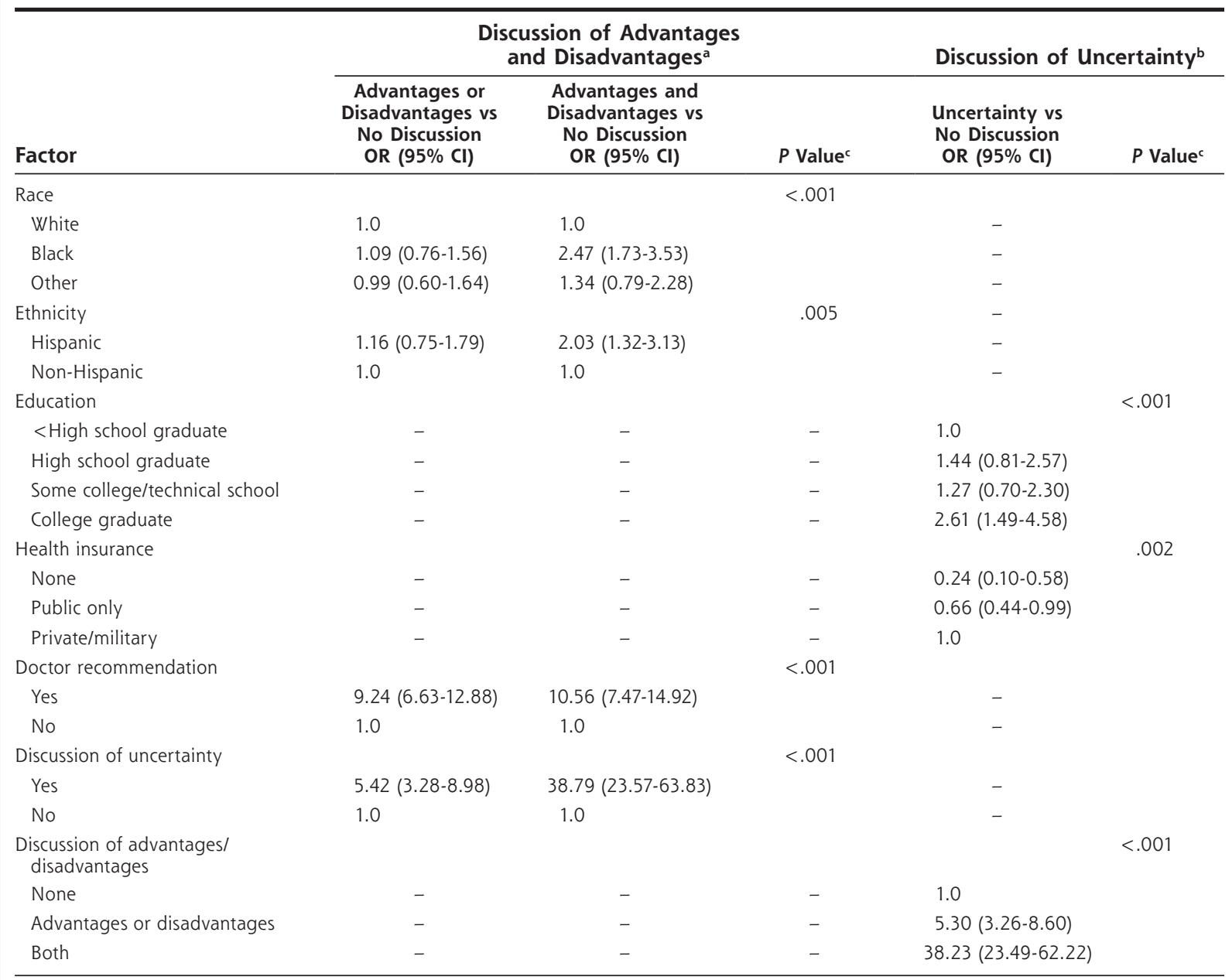

$\mathrm{OR}=$ odds ratio.

a Multivariable polytomous logistic regression model with discussion of advantages and disadvantages of PSA screening as the dependent variable $(n=3,260)$; analyses adjusted for age, education, poverty ratio, self-reported health status, number of chronic diseases, personal history of cancer, family history of prostate cancer, health insurance, usual source of medical care.

${ }^{b}$ Multivariable logistic regression model with discussion of uncertainty about PSA screening as the dependent variable ( $\left.n=3,260\right)$; analyses adjusted for age, poverty ratio, self-reported health status, number of chronic diseases, personal history of cancer, family history of prostate cancer, usual source of medical care.

'Wald $\chi^{2}$ test for association. 
ity of screening-related uncertainties. ${ }^{20}$ In the face of these barriers, attempts at shared decision making may not improve clinical outcomes, and the more practical approach may be to provide information about PSA screening apart from the clinical encounters, eg, through community-based screening programs or by means of decision aids delivered by nonphysician personnel. ${ }^{16}$ Accordingly, the more important outcome may be informed decision making rather than shared decision making.

Despite these limitations, our study provides important new evidence on the prevalence, nature, and potential influence of shared decision making in PSA screening. Shared decision making occurs infrequently, and its absence applies not only to screening but to nonscreening. Essential elements of shared decision making-physician-patient discussions of the advantages, disadvantages, and uncertainty associated with PSA screening_-are associated with screening intensity. Further work is needed to confirm these findings, to develop valid, feasible measures of informed and shared decision making for population surveillance, and to improve shared decision making in decisions both for and against PSA screening.

To read or post commentaries in response to this article, see it online at http://www.annfammed.org/content/11/4/306.

Key words: prostate-specific antigen; mass screening; decision making

Submitted October 6, 2012; submitted, revised, January 18, 2013; accepted February 5, 2013.

Author contributions: Dr Han had full access to all data in the study and takes responsibility for the integrity of the data and the accuracy of the data analysis.

Disclaimer: The findings and conclusions in this report are those of the authors and do not necessarily represent the official position of the National Cancer Institute or the Centers for Disease Control and Prevention.

Acknowledgments: We thank Richard Lee and Tim McNeel, Information Management Services, Inc, for programming and data analytic support, and Rachel Ballard-Barbash and Martin Brown for helpful comments on an earlier version of the manuscript.

\section{References}

1. Hall IJ, Taylor YJ, Ross LE, Richardson LC, Richards TB, Rim SH. Discussions about prostate cancer screening between U.S. primary care physicians and their patients. J Gen Intern Med. 2011;26(10): 1098-1104.

2. Chan EC, Vernon SW, Ahn C, Greisinger A. Do men know that they have had a prostate-specific antigen test? Accuracy of self-reports of testing at 2 sites. Am J Public Health. 2004;94(8):1336-1338.

3. Diefenbach PN, Ganz PA, Pawlow AJ, Guthrie D. Screening by the prostate-specific antigen test: what do the patients know? J Cancer Educ. 1996;11(1):39-44.
4. Federman DG, Goyal S, Kamina A, Peduzzi P, Concato J. Informed consent for PSA screening: does it happen? Eff Clin Pract. 1999;2(4): 152-157.

5. Volk RJ, Cass AR. The accuracy of primary care patients' self-reports of prostate-specific antigen testing. Am J Prev Med. 2002;22(1):56-58.

6. Allen JD, Othus MK, Hart A Jr, Mohllajee AP, Li Y, Bowen D. Do men make informed decisions about prostate cancer screening? Baseline results from the "take the wheel" trial. Med Decis Making. 2011;31(1):108-120.

7. Merenstein D. A piece of my mind. Winners and losers. JAMA. 2004;291(1):15-16.

8. Hoffman RM. Clinical practice. Screening for prostate cancer. N Engl J Med. 2011;365(21):2013-2019.

9. Pignone M. Weighing the benefits and downsides of prostate-specific antigen screening. Arch Intern Med. 2009;169(17):1554-1556.

10. Chou R, Croswell JM, Dana T, et al. Screening for prostate cancer: a review of the evidence for the U.S. Preventive Services Task Force. Ann Intern Med. 2011;155(11):762-771.

11. American Cancer Society. American Cancer Society recommendations for prostate cancer early detection. 2011. http://www.cancer.org/ Cancer/ProstateCancer/Morelnformation/ProstateCancerEarlyDetection/ prostate-cancer-early-detection-acs-recommendations. Accessed December 14, 2011

12. American Urological Association Education and Research I. Prostatespecific Antigen Best Practice Statement: 2009 Update. Linthicum, MD: American Urological Association Education and Research, Inc; 2009.

13. U.S. Preventive Services Task Force. Screening for prostate cancer: U.S. Preventive Services Task Force recommendation statement. Ann Intern Med. 2008;149(3):185-191.

14. Briss P, Rimer B, Reilley B, et al; Task Force on Community Preventive Services. Promoting informed decisions about cancer screening in communities and healthcare systems. Am J Prev Med. 2004;26(1):67-80.

15. Sheridan SL, Harris RP, Woolf SH; Shared Decision-Making Workgroup of the U.S. Preventive Services Task Force. Shared decision making about screening and chemoprevention. a suggested approach from the U.S. Preventive Services Task Force. Am J Prev Med. 2004;26(1):56-66.

16. Wolf AM, Wender RC, Etzioni RB, et al; American Cancer Society Prostate Cancer Advisory Committee. American Cancer Society guideline for the early detection of prostate cancer: update 2010. CA Cancer J Clin. 2010;60(2):70-98.

17. Chan EC, Vernon SW, O'Donnell FT, Ahn C, Greisinger A, Aga DW. Informed consent for cancer screening with prostate-specific antigen: how well are men getting the message? Am J Public Health. 2003;93(5):779-785.

18. Han PK, Coates RJ, Uhler RJ, Breen N. Decision making in prostatespecific antigen screening National Health Interview Survey, 2000. Am J Prev Med. 2006;30(5):394-404.

19. Hoffman RM, Couper MP, Zikmund-Fisher BJ, et al. Prostate cancer screening decisions: results from the National Survey of Medical Decisions (DECISIONS study). Arch Intern Med. 2009;169(17):1611-1618.

20. Brett AS, Ablin RJ. Prostate-cancer screening-what the U.S. Preventive Services Task Force left out. N Engl J Med. 2011;365(21): 1949-1951.

21. Volk RJ, Linder SK, Kallen MA, et al. Primary care physicians' use of an informed decision-making process for prostate cancer screening. Ann Fam Med. 2013;11(1):67-74.

22. U.S. Preventive Services Task Force. Screening for Prostate Cancer, Topic Page. 2011. http://www.uspreventiveservicestaskforce.org/ prostatecancerscreening.htm. 
23. Chou R, LeFevre ML. Prostate cancer screening - the evidence, the recommendations, and the clinical implications. JAMA. 2011;306(24): 2721-2722.

24. Jepson RG, Forbes CA, Sowden AJ, Lewis RA. Increasing informed uptake and non-uptake of screening: evidence from a systematic review. Health Expect. 2001;4(2):116-126.

25. Volk RJ, Wolf AM. Grading the new US Preventive Services Task Force prostate cancer screening recommendation. JAMA. 2011;306(24): 2715-2716.

26. McNaughton-Collins MF, Barry MJ. One man at a time-resolving the PSA controversy. N Engl J Med. 2011;365(21):1951-1953.

27. Miller DC, Hollenbeck BK. Missing the mark on prostate-specific antigen screening. JAMA. 2011;306(24):2719-2720.

28. Leader A, Daskalakis C, Braddock CH III, et al. Measuring informed decision making about prostate cancer screening in primary care. Med Decis Making. 2012;32(2):327-336.

29. National Center for Health Statistics. National Health Interview Survey: NHIS Survey Description. Hyattsville, MD: National Center for Health Statistics; 2001.

30. Braddock CH III, Edwards KA, Hasenberg NM, Laidley TL, Levinson W. Informed decision making in outpatient practice: time to get back to basics. JAMA. 1999;282(24):2313-2320.

31. Makoul G, Clayman ML. An integrative model of shared decision making in medical encounters. Patient Educ Couns. 2006;60(3): 301-312.

32. Moumjid N, Gafni A, Brémond A, Carrère MO. Shared decision making in the medical encounter: are we all talking about the same thing? Med Decis Making. 2007;27(5):539-546.

33. Cribb A, Entwistle VA. Shared decision making: trade-offs between narrower and broader conceptions. Health Expect. 2011;14(2):210-219.

34. Han PK, Klein WM, Arora NK. Varieties of uncertainty in health care: a conceptual taxonomy. Medl Decis Making. 2011;31(6):828-838.

35. Stacey D, Bennett CL, Barry MJ, et al. Decision aids for people facing health treatment or screening decisions. Cochrane Database Syst Rev. 2011;(10):CD001431.

36. Etzioni R, Berry KM, Legler JM, Shaw P. Prostate-specific antigen testing in black and white men: an analysis of medicare claims from 1991-1998. Urology. 2002;59(2):251-255.

37. Potosky AL, Feuer EJ, Levin DL. Impact of screening on incidence and mortality of prostate cancer in the United States. Epidemiol Rev. 2001;23(1):181-186.

38. Sirovich B, Gallagher PM, Wennberg DE, Fisher ES. Discretionary decision making by primary care physicians and the cost of U.S. Health care. Health Aff (Millwood). 2008;27(3):813-823.

39. Swan J, Breen N, Coates RJ, Rimer BK, Lee NC. Progress in cancer screening practices in the United States: results from the 2000 National Health Interview Survey. Cancer. 2003;97(6):1528-1540.
40. Voss JD, Schectman JM. Prostate cancer screening practices and beliefs. J Gen Intern Med. 2001;16(12):831-837.

41. Finney Rutten LJ, Meissner HI, Breen N, Vernon SW, Rimer BK. Factors associated with men's use of prostate-specific antigen screening: evidence from Health Information National Trends Survey. Prev Med. 2005;40(4):461-468.

42. Frosch DL, Kaplan RM, Felitti V. The evaluation of two methods to facilitate shared decision making for men considering the prostatespecific antigen test. J Gen Intern Med. 2001;16(6):391-398.

43. Frosch DL, Kaplan RM, Felitti VJ. A randomized controlled trial comparing internet and video to facilitate patient education for men considering the prostate specific antigen test. J Gen Intern Med. 2003;18(10):781-787.

44. Volk RJ, Cass AR, Spann SJ. A randomized controlled trial of shared decision making for prostate cancer screening. Arch Fam Med. 1999;8(4):333-340.

45. Volk RJ, Spann SJ, Cass AR, Hawley ST. Patient education for informed decision making about prostate cancer screening: a randomized controlled trial with 1-year follow-up. Ann Fam Med. 2003;1(1):22-28.

46. Brett AS. Ethical issues in risk factor intervention. Am J Med. 1984; 76(4):557-561.

47. Marshall KG. Prevention. How much harm? How much benefit? 4. The ethics of informed consent for preventive screening programs. CMAJ. 1996;155(4):377-383.

48. Sackett DL. The arrogance of preventive medicine. (MAJ. 2002; 167(4):363-364.

49. Sackett DL, Holland WW. Controversy in the detection of disease. Lancet. 1975;2(7930):357-359.

50. Sox HC Jr. Preventive health services in adults. N Engl J Med. 1994; 330(22):1589-1595.

51. Welch HG, Black WC. Evaluating randomized trials of screening. J Gen Intern Med. 1997;12(2):118-124.

52. Flocke SA, Gilchrist V. Physician and patient gender concordance and the delivery of comprehensive clinical preventive services. Med Care. 2005;43(5):486-492.

53. Saha S, Komaromy M, Koepsell TD, Bindman AB. Patient-physician racial concordance and the perceived quality and use of health care. Arch Intern Med. 1999;159(9):997-1004.

54. Arora NK. Interacting with cancer patients: the significance of physicians' communication behavior. Soc Sci Med. 2003;57(5):791-806.

55. Rauscher GH, Johnson TP, Cho YI, Walk JA. Accuracy of selfreported cancer-screening histories: a meta-analysis. Cancer Epidemiol Biomarkers Prev. 2008;17(4):748-757. 